\title{
Influences of structure and composition on the photoelectrochemical behaviour of anodic films on $\mathrm{Zr}$ and $\mathrm{Zr}-20$ at.\% Ti
}

\author{
M. Santamaria ${ }^{\text {a,* }}$, F. Di Quarto ${ }^{\text {a }}$, H. Habazaki ${ }^{b}$ \\ a Dipartimento di Ingegneria Chimica dei Processi e dei Materiali, Università di Palermo, Viale delle Scienze, 90128 Palermo, Italy \\ ${ }^{\mathrm{b}}$ Graduate School of Engineering, Hokkaido University, Sapporo 060-8628, Japan
}

Received 16 May 2007; received in revised form 21 September 2007; accepted 24 September 2007

Available online 29 September 2007

\begin{abstract}
A photoelectrochemical investigation on anodic films of different thickness grown on sputter-deposited $\mathrm{Zr}$ and $\mathrm{Zr}-20$ at.\% Ti was carried out. The estimated optical band gap and flat band potential of thick $\left(U_{\mathrm{F}} \geq 50 \mathrm{~V}\right)$ anodic films were related to their crystalline structure and compared with those obtained for thinner $\left(U_{\mathrm{F}} \leq 8 \mathrm{~V} / \mathrm{SCE}\right)$ anodic oxides having undetermined crystalline structure. The $E_{\mathrm{g}}$ values obtained by photocurrent spectroscopy were also compared with the experimental band gap estimated by other optical ex situ techniques and with the available theoretical estimates of the zirconia electronic structures in an attempt to reconcile the wide range of band gap data reported in the literature. Finally, the optical band gap and flat band potential values obtained for tetragonal $\mathrm{Zr}_{0.8} \mathrm{Ti}_{0.2} \mathrm{O}_{2}$ mixed oxide were compared with that expected on the basis of a correlation between $E_{\mathrm{g}}$ and the film composition.
\end{abstract}

(C) 2007 Elsevier Ltd. All rights reserved.

Keywords: Zirconium; Zr-Ti alloys; Passive films; Photoelectrochemistry; Band gap

\section{Introduction}

Zirconia is a technologically important material due to its high strength and stability at high temperatures and its excellent dielectric properties. These features make $\mathrm{ZrO}_{2}$ very useful in a wide range of applications in the ceramic engineering [1], as oxygen sensor in fuel cell [2] and as catalytic support medium [3]. Zirconia is one of the most radiation-resistant ceramics currently known $[4,5]$ and therefore has a particular importance in the nuclear industry, where zirconium-based alloys are frequently employed due to their excellent mechanical properties and good corrosion resistance [6,7]. Moreover, in the last years $\mathrm{ZrO}_{2}$ has been proposed as a gate dielectric material in metaloxide semiconductor devices [8,9].

All these applications require a deep understanding of the structural and electronic properties of $\mathrm{ZrO}_{2}$ in its polymorphs (cubic, tetragonal or monoclinic phases) and this justifies the large number of papers published in the last years reporting on both theoretical predictions and experimental investigations of

\footnotetext{
* Corresponding author. Tel.: +39 0916567287 ; fax: +39 0916567280.

E-mail address: santamaria@ dicpm.unipa.it (M. Santamaria).
}

the solid state properties of this material. However, a critical analysis of the theoretical results evidences a large discrepancy in the estimated band gap value of $\mathrm{ZrO}_{2}$ as a function of its crystallographic structure, while the experimental estimates are strongly dependent on the employed technique. The estimate of the band gap value of $\mathrm{ZrO}_{2}$ polymorphs is further complicated by the use of dopants to stabilize at room temperature the high temperature stable phases (i.e. cubic and tetragonal) of zirconia. The large amount of stabilizers modifies the composition of the investigated oxide and, thus, influences in some way its electronic structure.

As for theoretical studies, the electronic and structural properties of $\mathrm{ZrO}_{2}$ have been widely examined using Hartree-Fock $[10,11]$ or density functional theory (DFT) [12-19]. The role of doping in stabilizing the phases has been also investigated both at the Hartree-Fock [20] or DFT [21-25] levels. In some cases the theoretical predictions have been compared to the experimental results, as in ref. [26] where vacuum ultraviolet (VUV) Spectroscopy has been employed for determining the electronic structure of cubic, tetragonal and monoclinic $\mathrm{ZrO}_{2}$. More recently electron energy loss spectroscopy (EELS) has been proposed as a useful method for providing information on the chemical and crystallographic characteristics of a mate- 
rial, as well as on its electronic structure and has been already employed with pure and doped $\mathrm{ZrO}_{2}$ [27-31]. The main drawback of this technique is the interpretation of obtained spectra, which requires a complex theoretical framework for permitting an abinitio calculation of the EELS spectra to be compared with the experimental ones. A very good example of this approach is extensively described in ref. [31], where the results for the electronic structure of zirconia polymorphs are discussed in the context of an analysis of existing (sometimes controversial) literature. French et al. [26] reported for single crystal monoclinic zirconia band gap values between 5.8 and $7.1 \mathrm{eV}$ depending on the fitted energy region in the VUV absorption spectra, but lower values have been estimated by optical absorption measurements $(\sim 5.2 \mathrm{eV}$, see ref. [32]) and by EELS experiments $(\sim 4 \mathrm{eV}$ $[28,29,33])$. Moreover, UV-diffuse reflectance spectra [34] show large absorbance below $5.4 \mathrm{eV}$ down to $3.5 \mathrm{eV}$ in pure tetragonal $\left(\mathrm{t}-\mathrm{ZrO}_{2}\right)$ and monoclinic $\left(\mathrm{m}-\mathrm{ZrO}_{2}\right)$ zirconia.

The EELS experiments and their interpretation on the base of theoretical calculations allowed Dash and co-workers to estimate direct band gap of 5.3 and $5.0 \mathrm{eV}$ for $\mathrm{m}-\mathrm{ZrO}_{2}$ and $\mathrm{t}-\mathrm{ZrO}_{2}$, respectively, even if the fitting of the low energy region of the spectra also in this case allowed to estimate an indirect gap of $3.8 \mathrm{eV}$ for monoclinic zirconia. However, a critical analysis of the experimental EELS band gap values and of those theoretically estimated brought the authors to conclude that the fitting of the low energy edge of the EESL spectra did not allow to determine the fundamental gap and, in order to reconcile VUV and EELS results for $\mathrm{m}-\mathrm{ZrO}_{2}$, they attributed the low energy part of the EELS spectrum to electronic excitations from defect states. Their location is suggested to be at $2 \mathrm{eV}$ above the top of the intrinsic valence band, in agreement with previous theoretical estimations [22].

In this frame it is interesting to mention the results on the electronic properties of zirconia obtained by photoelectrochemistry. Newmark and Stimming [35] measured the photocurrent response of thin anodic $\mathrm{ZrO}_{2}$ films estimating an indirect band gap value of $4.8 \mathrm{eV}$, even if they also observed a photocurrent tailing down to $3 \mathrm{eV}$. The same behaviour was observed by Goossens et al. [36], who attributed the sub-band gap photocurrent to optical transitions involving localized states inside the gap, related to the presence of oxygen vacancies. Another possible explanation for this phenomenon was suggested by Di Quarto et al. [37], who hypothesised for anodic zirconia grown on chemical and electrochemical polished mechanical treated cast $\mathrm{Zr}$ a duplex structure, constituted by an anhydrous wide band gap $\mathrm{ZrO}_{2}$ layer at the metal/film interface, and a hydrated zirconium oxide layer at the film/electrolyte interface having a band gap lower $(2.75 \mathrm{eV})$ with respect to the anhydrous counterpart. More recently other researchers $[38,39]$ have interpreted their photoelectrochemical results on $\mathrm{ZrO}_{2}$ on the base of this hypothesis. However, we have to say that a compelling experimental evidence allowing to reach a final conclusion on the origin of the sub-band gap photocurrent in anodic films is still missing.

Recently the structure and composition of anodic films on sputter-deposited $\mathrm{Zr}$ and $\mathrm{Zr}-20$ at.\% Ti alloy have been extensively studied by means of grazing incidence X-ray diffraction (GIXRD), transmission electron microscopy (TEM), glow dis- charge optical emission spectroscopy (GDOES) and Rutherford back scattering (RBS) [40]. According to the experimental results of this work, crystalline films of uniform composition are formed during the anodizing of both samples at formation voltages $U_{\mathrm{F}} \geq 50 \mathrm{~V}$. On the base of these structural and compositional information, we performed a photoelectrochemical investigation on anodic films grown on sputter-deposited $\mathrm{Zr}$ and $\mathrm{Zr}-20$ at.\% Ti with a characterized crystalline structure aimed to get information on their electronic properties, i.e. band gap and flat band potential. Both these data are of paramount importance in deriving the energetics of metal/oxide/electrolyte junctions as well as of other metal/insulator/metal (MIM) structure. The results will be compared with those obtained for anodic films with undetermined crystalline structure grown on sputtered samples to lower formation voltages $\left(U_{\mathrm{F}} \leq 8 \mathrm{~V} / \mathrm{SCE}\right)$ and with previous photoelectrochemical data on anodic zirconia grown on cast $\mathrm{Zr}$ after mechanical and/or chemical cleaning. Moreover, a summary of recent experimental band gap estimated with other optical techniques and the available theoretical estimates of the zirconia electronic structure will be performed in an attempt to reconcile the wide range of band gap values reported in the literature. Finally, the influence of $\mathrm{Ti}^{4+}$ on the photoelectrochemical behaviour of anodic films on $\mathrm{Zr}-20$ at.\% Ti with respect to the anodic films on pure $\mathrm{Zr}$ will be discussed and interpreted on the basis of a correlation between the band gap values and the film composition [41].

\section{Experimental}

$\mathrm{Zr}$ and $\mathrm{Zr}-20$ at.\% Ti alloy films were prepared by dc magnetron sputtering. Targets consisted of a $99.9 \%$ zirconium disk, of $100 \mathrm{~mm}$ diameter, with an appropriate number of $99.9 \%$ titanium disks, of $20 \mathrm{~mm}$ diameter, located symmetrically on the erosion region for preparation of the alloys. Substrates were glass plates, which provided smooth and flat surfaces. In order to obtain alloy films of uniform thickness and composition, the substrate holders were rotated around the central axis of the chamber, as well as about their own axes, during sputter deposition [40].

Anodizing was undertaken in $0.1 \mathrm{M}$ ammonium pentaborate (ABE) and $0.5 \mathrm{M} \mathrm{H}_{2} \mathrm{SO}_{4}$ electrolytes at $298 \mathrm{~K}$ without any surface pretreatment. A $0.1 \mathrm{M}$ sodium acetate in acetic acid (SAAC) solution containing $2 \% \mathrm{w} / \mathrm{v}$ of water and a $0.1 \mathrm{M} \mathrm{NaOH}$ solutions were also employed for anodizing pure $\mathrm{Zr}$. A saturated calomel electrode (SCE) was employed as reference electrode.

The experimental set-up employed for the photoelectrochemical investigations is described elsewhere [41]: it consists of a $450 \mathrm{~W}$ UV-vis xenon lamp coupled with a monochromator (Kratos), which allows monochromatic irradiation of the specimen surface through the electrochemical cell quartz windows. A two-phase lock-in amplifier (EG \& G) was used in connection with a mechanical chopper (frequency: $13 \mathrm{~Hz}$ ) in order to separate the photocurrent from the total current circulating in the cell due to the potentiostatic control. Photocurrent spectra reported below are corrected for the relative photon efficiency of the light source at each wavelength, so that the photocurrent yield in arbitrary current units is represented in the $Y$-axis. 


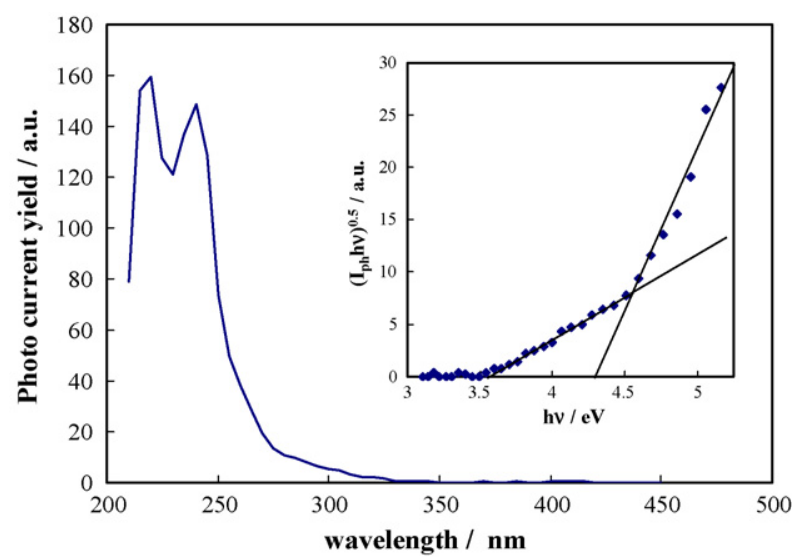

Fig. 1. Photocurrent spectrum relating to an air formed film on $\mathrm{Zr}$ recorded at $-0.3 \mathrm{~V}$ (SCE) in $0.1 \mathrm{M} \mathrm{ABE}$. Inset: determination of the optical bad gap assuming non-direct transitions.

\section{Results}

\subsection{Films on sputter-deposited $\mathrm{Zr}$}

Air formed films resulted photoactive in both ammonium pentaborate and sulphuric acid electrolyte. In both the solutions spectra display a short wavelength region where anodic photocurrent is measured at the open circuit potential, whilst at longer wavelengths the onset of a cathodic photocurrent is sometimes observed. In order to overcome any uncertainty in the determination of the band gap of the air formed films arising from the simultaneous presence of anodic and cathodic photocurrent, anodic photocurrent spectra have been recorded at electrode potential more positive than $U_{\mathrm{OC}}$. The increment of polarizing voltage has been kept low $(\cong 0.3 \mathrm{~V})$ in order to not affect appreciably the nature of the air formed film. Thus photocurrent spectra have been recorded at $-0.3 \mathrm{~V}$ (SCE) in $0.1 \mathrm{M}$ $\mathrm{ABE}$ and $0 \mathrm{~V}$ (SCE) in $0.5 \mathrm{M} \mathrm{H}_{2} \mathrm{SO}_{4}$. By assuming indirect (nondirect for amorphous materials) optical transitions it is possible to derive from the anodic photocurrent spectra the optical band gap value, $E_{\mathrm{g}}$, of the films according to the following equation [41]:

$\left(I_{\mathrm{ph}} h v\right)^{0.5} \propto\left(h v-E_{\mathrm{g}}\right)$

where $I_{\mathrm{ph}}$ is the photocurrent corrected for the relative photon efficiency of the light source at each wavelength. In both cases two extrapolations were possible (see inset of Fig. 1) giving two possible band gap values: $E_{\mathrm{g} 1}=3.5 \mathrm{eV}$ and $E_{\mathrm{g} 2}=4.3 \mathrm{eV}$ by fitting the region of low and high energy, respectively.

In order to study the influence of thickness and of $\mathrm{pH}$ of the anodizing electrolyte on the structure and composition of anodic films on zirconium, pure sputtered $\mathrm{Zr}$ samples were anodized to different formation voltages and in different solutions. For each sample photocurrent spectra were recorded in order to estimate their band gap value.

In Table 1 we summarize the estimated band gap values for anodic films grown potentiodynamically to $8 \mathrm{~V}$ (SCE) at $100 \mathrm{mV} \mathrm{s}^{-1}$ as a function of the anodizing electrolyte. In any case an anodic photocurrent tail has been observed in the low
Table 1

Indirect optical band gap values at low $\left(E_{\mathrm{g} 1}\right)$ and at high $\left(E_{\mathrm{g} 2}\right)$ photon energies and Fowler thresholds for anodic films grown on sputter-deposited $\mathrm{Zr}$ to $8 \mathrm{~V}$ (SCE) at $100 \mathrm{mV} \mathrm{s}^{-1}$ as a function of the anodizing electrolyte

\begin{tabular}{llll}
\hline $\begin{array}{l}\text { Anodizing and } \\
\text { characterizing electrolyte }\end{array}$ & $E_{\mathrm{g} 1}(\mathrm{eV})$ & $E_{\mathrm{g} 2}(\mathrm{eV})$ & $E_{\mathrm{th}}(\mathrm{eV})$ \\
\hline $0.5 \mathrm{M} \mathrm{H}_{2} \mathrm{SO}_{4}$ & 3.42 & 4.75 & 1.84 \\
$0.1 \mathrm{M} \mathrm{NaOH}$ & 3.30 & 4.70 & 1.75 \\
$\mathrm{SAAC}$ & 3.35 & 4.80 & 1.78 \\
\hline
\end{tabular}

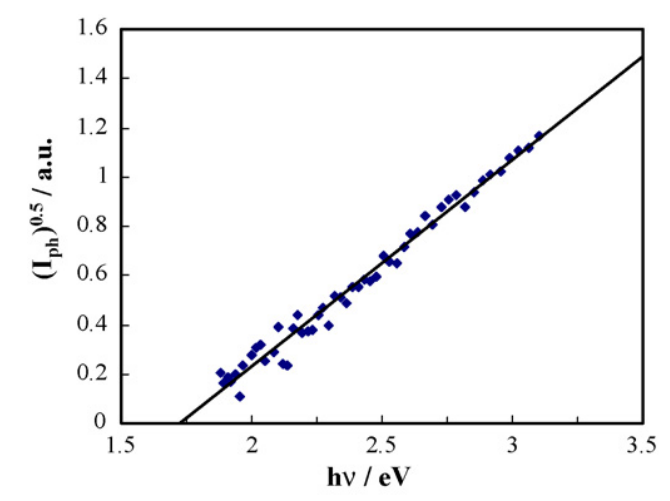

Fig. 2. Fowler plot relating to an anodic film grown to $8 \mathrm{~V}$ (SCE) on $\mathrm{Zr}$ in SAAC, recorded in the same electrolyte at $-1.2 \mathrm{~V}$ (SCE).

energy part of the spectrum which gives an indirect $E_{\mathrm{g}}$ value of $3.35-3.50 \mathrm{eV}$, while the fitting of the high energy region in the $\left(I_{\mathrm{ph}} h v\right)^{0.5}$ versus $h v$ plot gives a band gap value of $4.75 \pm 0.05 \mathrm{eV}$. The presence in the cathodic spectra of a photocurrent tail at very low $(h v<3.2 \mathrm{eV})$ irradiating energy is detected (see Fig. 2), presumably due to an electron injection process from the metal Fermi level to the oxide conduction band. A threshold, $E_{\mathrm{th}}$, of $\sim 1.8 \mathrm{eV}$ associated to this process can be estimated according to Fowler law [41]:

$\left(I_{\mathrm{ph}}\right)^{0.5} \propto\left(h v-E_{\mathrm{th}}\right)$

Regardless of the electrolyte solution, an almost constant internal photoemission threshold of $1.80 \pm 0.05 \mathrm{eV}$ can be estimated (see Fig. 2 and Table 1). According to Table 1, a preliminary conclusion is that the $\mathrm{pH}$ of the anodizing solution $(0.3 \leq \mathrm{pH} \leq 13)$ and water content (very low in SAAC) do not influence the photoelectrochemical behaviour of these films.

The effect of the thickness and/or of the crystalline structure (see below) on the estimated band gap value is summarized in Table 2, where we report $E_{\mathrm{g}}$ as a function of the formation volt-

Table 2

Indirect optical band gap values at low $\left(E_{\mathrm{g} 1}\right)$ and at high $\left(E_{\mathrm{g} 2}\right)$ photon energies for anodic films grown on sputter-deposited $\mathrm{Zr}$ in $0.1 \mathrm{M} \mathrm{ABE}$ as a function of the anodizing conditions

\begin{tabular}{lll}
\hline Anodizing conditions & $E_{\mathrm{g} 1}(\mathrm{eV})$ & $E_{\mathrm{g} 2}(\mathrm{eV})$ \\
\hline Air formed film & 3.46 & 4.30 \\
$U_{\mathrm{F}}=4 \mathrm{~V}$ (SCE) at $20 \mathrm{mV} \mathrm{s}^{-1}$ & 3.40 & 4.50 \\
$U_{\mathrm{F}}=8 \mathrm{~V}(\mathrm{SCE})$ at $100 \mathrm{mV} \mathrm{s}^{-1}$ & 3.35 & 4.80 \\
$U_{\mathrm{F}}=50 \mathrm{~V}$ at $5 \mathrm{~mA} \mathrm{~cm}^{-2}$ & 3.30 & 4.85 \\
$U_{\mathrm{F}}=100 \mathrm{~V}$ at $5 \mathrm{~mA} \mathrm{~cm}^{-2}$ & 3.28 & 4.85 \\
\hline
\end{tabular}




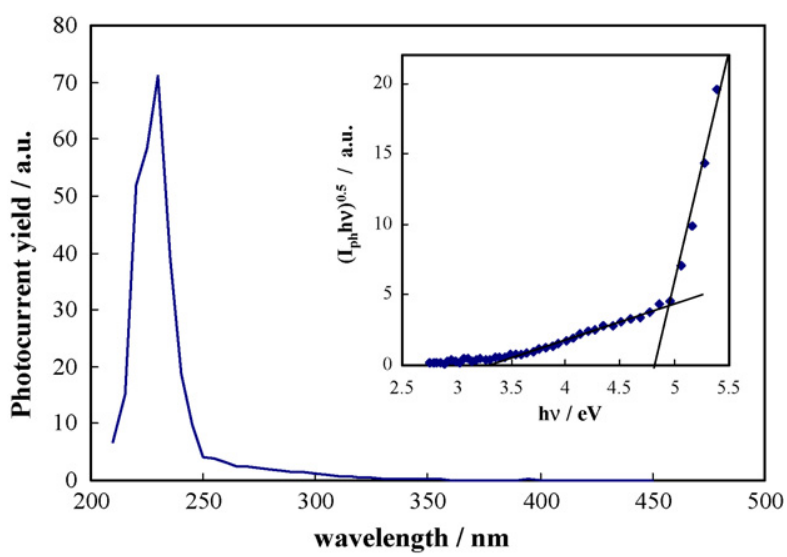

Fig. 3. Photocurrent spectrum relating to an anodic film grown to $100 \mathrm{~V}$ on $\mathrm{Zr}$ in $0.1 \mathrm{M} \mathrm{ABE}$ at $5 \mathrm{~mA} \mathrm{~cm}^{-2}$, recorded in the same electrolyte at $8 \mathrm{~V}$ (SCE). Inset: determination of the optical bad gap assuming non-direct transitions.

age. The presence of a long photocurrent tail in the low energy region of the photocurrent spectra is a common feature of the investigated thickness, as shown in Fig. 3 where we report the photocurrent spectrum relating to an anodic film grown galvanostatically to $100 \mathrm{~V}$ in $0.1 \mathrm{M} \mathrm{ABE}$ at $5 \mathrm{~mA} \mathrm{~cm}^{-2}$, which was found to be monoclinic $\mathrm{ZrO}_{2}$, according to the GIXRD analysis [40]. The extrapolated $E_{\mathrm{g}}$ values in the $\left(I_{\mathrm{ph}} h v\right)^{0.5}$ versus $h v$ plot are 4.80 and $3.28 \mathrm{eV}$ by fitting the high and the low energy region of the spectrum, respectively (see inset of Fig. 3). Very close $E_{\mathrm{g}}$ values were found for $8 \mathrm{~V}$ (SCE) and $50 \mathrm{~V}$ films, while for the thinnest investigated zirconia layers (i.e. air formed or anodized to 4 V/SCE) the extrapolated energy thresholds are slightly different. An $E_{\mathrm{g}}$ value between 4.2 and $4.5 \mathrm{eV}$ can be estimated from the high-energy region, while a value of $3.4-3.5 \mathrm{eV}$ was derived from the low energy region.

Photocurrent versus electrode potential (photocharacteristics) curves at constant irradiating wavelength were recorded for all the investigated anodic oxides on $\mathrm{Zr}$, by scanning the electrode potential in the cathodic direction at $10 \mathrm{mV} \mathrm{s}^{-1}$. In any case an inversion of the photocurrent sign was revealed, thus indicating a behaviour typical of insulating materials (see Fig. 4a). The presence of stationary cathodic photocurrent was also confirmed by comparing the current circulating in the dark and under irradiation. For $\lambda=230 \mathrm{~nm}\left(h v>E_{\mathrm{g}}\right)$, the $I_{\mathrm{ph}}$ versus $U_{\mathrm{E}}$ curves were fitted according to a power law (see Fig. $4 \mathrm{~b}$ ):

$\left(I_{\mathrm{ph}}\right)^{n} \propto\left(U_{\mathrm{E}}-V^{*}\right)$

The best fitting exponent, $n$, and the extrapolated zero photocurrent potential, $V^{*}$, which can be assumed as a reasonable estimate of the flat band potential, $U_{\mathrm{FB}}$, are reported in Table 3 . A $U_{\mathrm{FB}}=-1.25 \pm 0.05 \mathrm{~V}$ (SCE) at $\mathrm{pH} 8.5$ can be assumed for anodic $\mathrm{ZrO}_{2}$ by averaging the estimated values as a function of the formation voltage. The more anodic values estimated for films formed and characterized in $0.5 \mathrm{M} \mathrm{H}_{2} \mathrm{SO}_{4}$ electrolyte reported in Table 3, are in agreement with the theory, which predicts a dependence of $U_{\mathrm{FB}}$ on the $\mathrm{pH}$ according to the relationship [42]:

$\mathrm{U}_{\mathrm{FB}}=$ const. $-0.059 \mathrm{pH}$
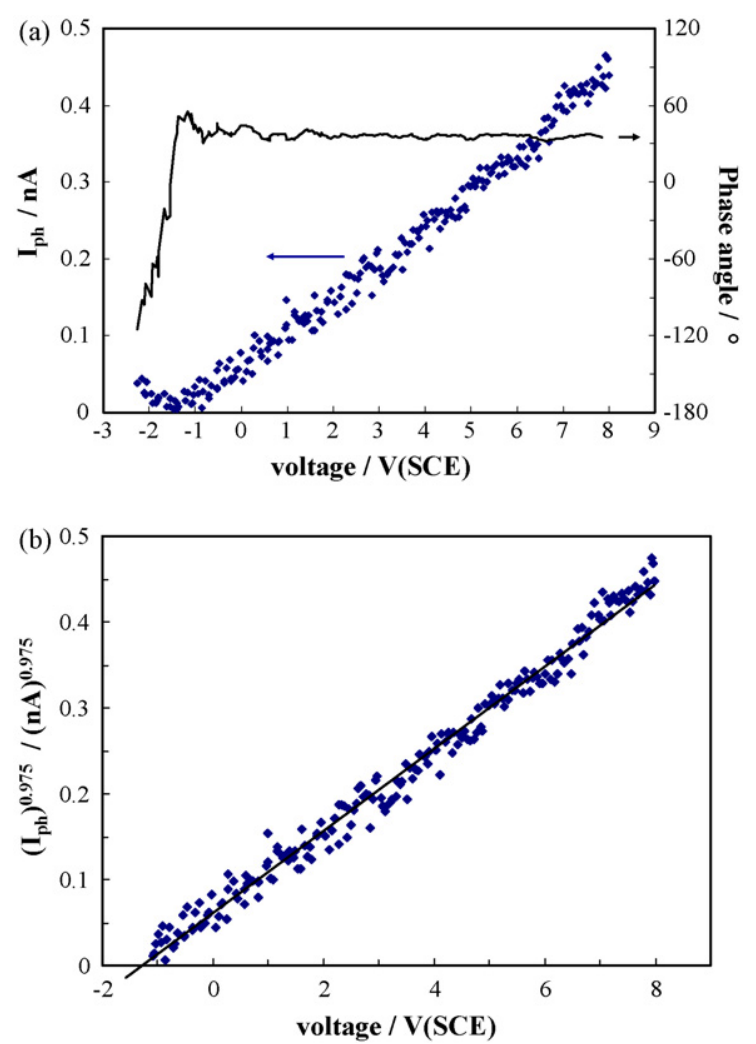

Fig. 4. (a) Photocurrent magnitude and phase angle vs. electrode potential relating to an anodic film grown to $100 \mathrm{~V}$ on $\mathrm{Zr}$ in $0.1 \mathrm{M} \mathrm{ABE}$ at $5 \mathrm{mAcm}^{-2}$. $\lambda=230 \mathrm{~nm}$ and $v_{\text {scan }}=10 \mathrm{mV} \mathrm{s}^{-1}$. (b) $\left(I_{\mathrm{ph}}\right)^{0.975} \mathrm{vs}$. electrode potential plot.

Concerning the best fit exponents, it is noteworthy to mention that for the investigated films the photocharacteristics displayed a supralinear $(n<1)$ behaviour with $\mathrm{n}$ increasing with increasing $U_{\mathrm{F}}$. For insulating crystalline films a linear dependence of the measured photocurrent on the applied potential is expected in absence of trapping phenomena which can modify the electric field distribution across the layer [43]. The significant supralinear behaviour experimentally evidenced for films with $U_{\mathrm{F}} \leq 50 \mathrm{~V}$ can be explained by the presence of surface and bulk recombination phenomena involving the photogenerated carriers, as well as to geminate recombination effects generally occurring in any material where the photogenerated carriers display very low mobility (e.g. amorphous films). In presence of geminate recombination effects an influence of the electric field

Table 3

Parameters obtained by fitting according to Eq. (3) the experimental photocharacteristics recorded for anodic films on sputter-deposited $\mathrm{Zr}$

\begin{tabular}{lll}
\hline Anodizing conditions & $n$ & $V^{* / V}(\mathrm{SCE})$ \\
\hline Air formed film in $0.5 \mathrm{M} \mathrm{H}_{2} \mathrm{SO}_{4}$ & 0.60 & -0.74 \\
$U_{\mathrm{F}}=4 \mathrm{~V}$ (SCE) at $20 \mathrm{mV} \mathrm{s}^{-1}$ in $0.5 \mathrm{M} \mathrm{H}_{2} \mathrm{SO}_{4}$ & 0.825 & -0.78 \\
Air formed film in $0.1 \mathrm{M} \mathrm{ABE}^{-1}$ & 0.725 & -1.25 \\
$U_{\mathrm{F}}=4 \mathrm{~V}$ (SCE) at $20 \mathrm{mV} \mathrm{s}^{-1}$ in $0.1 \mathrm{M} \mathrm{ABE}$ & 0.75 & -1.23 \\
$U_{\mathrm{F}}=50 \mathrm{~V}$ at $5 \mathrm{~mA} \mathrm{~cm}^{-2}$ in $0.1 \mathrm{M} \mathrm{ABE}$ & 0.85 & -1.26 \\
$U_{\mathrm{F}}=100 \mathrm{~V}$ at $5 \mathrm{~mA} \mathrm{~cm}^{-2}$ in $0.1 \mathrm{M} \mathrm{ABE}$ & 0.975 & -1.29
\end{tabular}

$\lambda=230 \mathrm{~nm}$ and $v_{\text {scan }}=10 \mathrm{mV} \mathrm{s}^{-1}$. 
and of the photon energy through the thermalization distance, $r_{0}$, of the photocarriers [41] is expected on the efficiency of photocarriers generation, $\eta_{\mathrm{g}}$, which can explain the supralinear behaviour of the photocharacteristics. The best fit exponent approaching to 1 in the case of $100 \mathrm{~V}$ anodic film suggests an independence of $I_{\mathrm{ph}}$ on $\eta_{\mathrm{g}}$, owing to the almost constant efficiency of charge separation in the exploited potential (i.e. electric field) range [41].

As a general trend, for irradiating energies lower than $E_{\mathrm{g} 1}$ the inversion potential was shifted at more anodic potential.

\subsection{Films on sputter-deposited $\mathrm{Zr}-20 \mathrm{at} . \% \mathrm{Ti}$}

Following a procedure very similar to that described for films on $\mathrm{Zr}$, photoelectrochemical behaviour of both air formed and anodic films on $\mathrm{Zr}-20$ at.\% Ti was studied. A band gap of $4.15 \mathrm{eV}$ was estimated for the air formed films by assuming indirect optical transitions. Slightly lower $(\sim 4 \pm 0.05 \mathrm{eV})$ band gap values were estimated after anodizing to $4 \mathrm{~V}$ (SCE) in both $0.1 \mathrm{M}$ $\mathrm{ABE}$ and $0.5 \mathrm{M} \mathrm{H}_{2} \mathrm{SO}_{4}$ by assuming non-direct optical transitions (see Table 4), whilst an appreciably lower optical band gap value was obtained for $100 \mathrm{~V}$ anodic films grown in the same electrolytes. In Fig. 5a we report the photocurrent spectrum relating to $\mathrm{Zr}-20$ at.\% Ti after anodizing to $100 \mathrm{~V}$ in $0.1 \mathrm{M}$ $\mathrm{ABE}$ at $5 \mathrm{~mA} \mathrm{~cm}{ }^{-2}$, which has the crystalline structure of $\mathrm{t}-\mathrm{ZrO}_{2}$ according to ref. [40]. An indirect band gap value of $3.68 \mathrm{eV}$ can be estimated for the Ti containing mixed oxide, as shown in Fig. $5 b$ according to Eq. (1). A higher band gap value is
Table 4

Indirect optical band gap values for anodic films grown on sputter-deposited $\mathrm{Zr}-20$ at. $\% \mathrm{Ti}$ as a function of the anodizing conditions

\begin{tabular}{lll}
\hline Anodizing conditions & Electrolyte & $E_{\mathrm{g}}(\mathrm{eV})$ \\
\hline Air formed film & $0.5 \mathrm{M} \mathrm{H}_{2} \mathrm{SO}_{4}$ & 4.10 \\
$U_{\mathrm{F}}=4 \mathrm{~V}$ (SCE) at $20 \mathrm{mV} \mathrm{s}^{-1}$ & $0.5 \mathrm{M} \mathrm{H}_{2} \mathrm{SO}_{4}$ & 3.95 \\
$U_{\mathrm{F}}=100 \mathrm{~V}$ at $5 \mathrm{~mA} \mathrm{~cm}^{-2}$ & $0.5 \mathrm{M} \mathrm{H}_{2} \mathrm{SO}_{4}$ & 3.60 \\
Air formed film & $0.1 \mathrm{M} \mathrm{ABE}$ & 4.10 \\
$U_{\mathrm{F}}=4 \mathrm{~V}$ (SCE) at $20 \mathrm{mV} \mathrm{s}^{-1}$ & $0.1 \mathrm{M} \mathrm{ABE}$ & 4.00 \\
$U_{\mathrm{F}}=100 \mathrm{~V}$ at $5 \mathrm{~mA} \mathrm{~cm}^{-2}$ & $0.1 \mathrm{M} \mathrm{ABE}$ & 3.65 \\
\hline
\end{tabular}

derived by assuming direct optical transitions and according to the following equation:

$\left(I_{\mathrm{ph}} h v\right)^{2} \propto\left(h v-E_{\mathrm{g}}\right)$

At variance with thinner films, for $100 \mathrm{~V}$ anodic oxides a wide linear region is present in $\left(I_{\mathrm{ph}} h v\right)^{2}$ versus $h v$ plot (see Fig. 5c), thus indicating that also direct transitions are operating in the investigated oxide and allowing to estimate a direct band gap of $4.38 \mathrm{eV}$. Both the indirect and direct band gap are not sensitively influenced by the polarizing voltage.

In Fig. 6a we report the photocharacteristic relating to the $100 \mathrm{~V}$ anodic film of Fig. 5, recorded at $240 \mathrm{~nm}$ by scanning the polarizing voltage toward the cathodic direction at $10 \mathrm{mV} \mathrm{s}^{-1}$. An inversion of the photocurrent sign has been evidenced as marked by the abrupt change in the photocurrent phase angle shown in Fig. 6a. The presence of a cathodic steady state photocurrent was confirmed by recording the total current in the
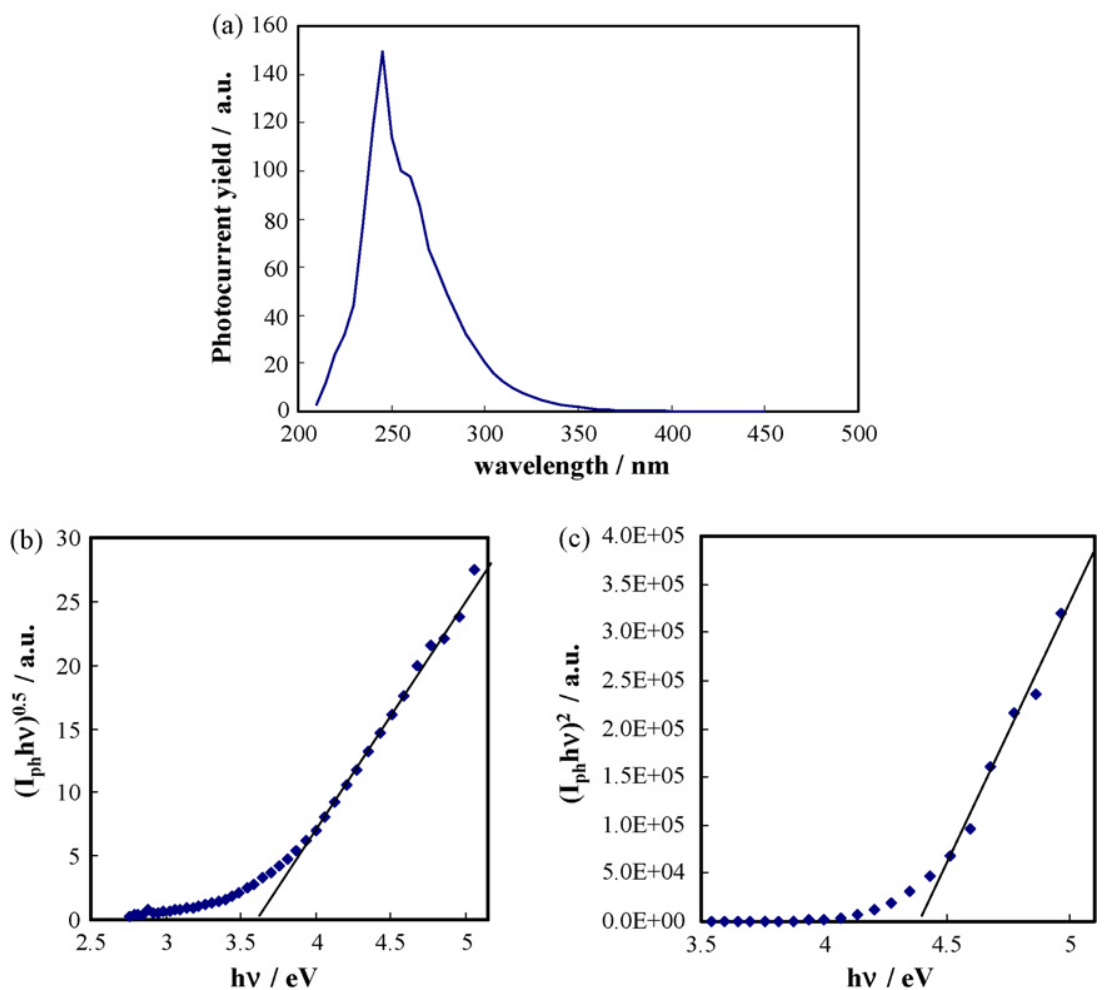

Fig. 5. (a) Photocurrent spectrum relating to an anodic film grown to $100 \mathrm{~V}$ on $\mathrm{Zr}-20$ at. $\% \mathrm{Ti}$ in $0.1 \mathrm{M} \mathrm{ABE}$ at $5 \mathrm{~mA} \mathrm{~cm}{ }^{-2}$, recorded in the same electrolyte at $8 \mathrm{~V}$ (SCE). (b) Determination of the optical bad gap assuming non-direct transitions. (c) Determination of the optical bad gap assuming direct transitions. 

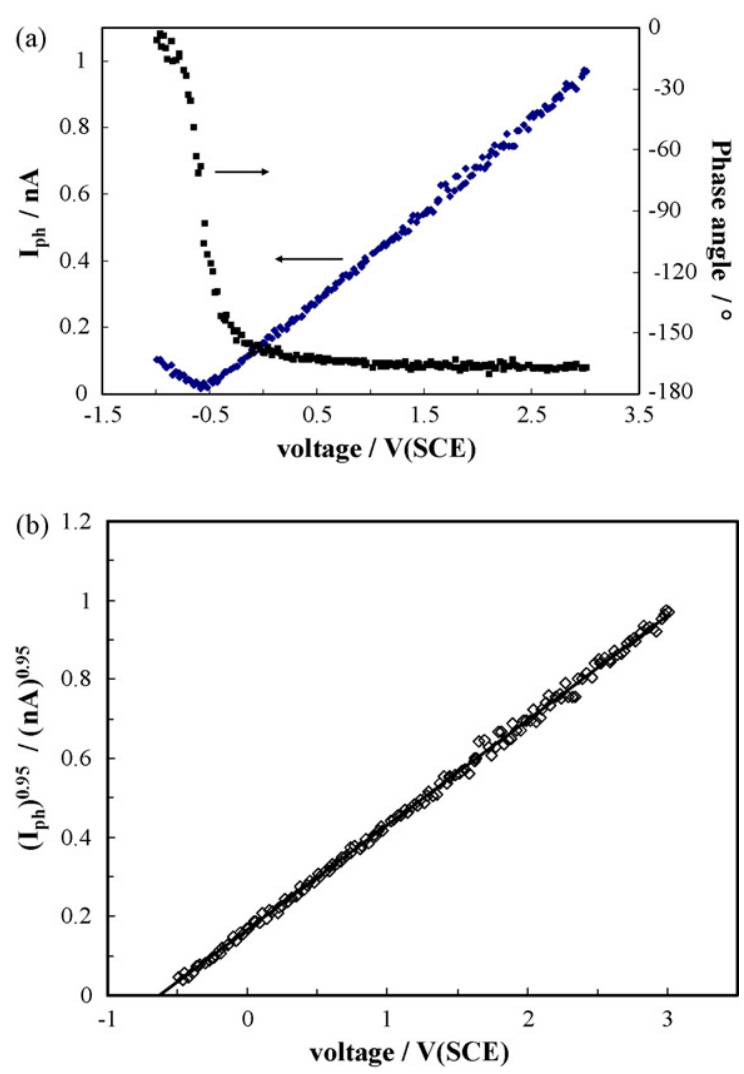

Fig. 6. (a) Photocurrent magnitude and phase angle vs. electrode potential relating to an anodic film grown to $100 \mathrm{~V}$ on $\mathrm{Zr}-20$ at. $\% \mathrm{Ti}$ in $0.1 \mathrm{M} \mathrm{ABE}$ at $5 \mathrm{~mA} \mathrm{~cm}^{-2} \cdot \lambda=240 \mathrm{~nm}$ and $v_{\text {scan }}=10 \mathrm{mV} \mathrm{s}^{-1}$. (b) $\left(I_{\mathrm{ph}}\right)^{0.95}$ vs. electrode potential plot.
Table 5

Parameters obtained by fitting according to Eq. (3) the experimental photocharacteristics recorded for anodic films on sputter-deposited $\mathrm{Zr}-20$ at.\% Ti

\begin{tabular}{lll}
\hline Anodizing conditions & $n$ & $V^{* / V(\mathrm{SCE})}$ \\
\hline$U_{\mathrm{F}}=4 \mathrm{~V}(\mathrm{SCE})$ in $0.5 \mathrm{M} \mathrm{H}_{2} \mathrm{SO}_{4}$ & 0.60 & -0.08 \\
$U_{\mathrm{F}}=100 \mathrm{~V}$ in $0.5 \mathrm{M} \mathrm{H}_{2} \mathrm{SO}_{4}$ & 0.90 & -0.13 \\
$U_{\mathrm{F}}=4 \mathrm{~V}(\mathrm{SCE})$ in $0.1 \mathrm{M} \mathrm{ABE}$ & 0.58 & -0.62 \\
$U_{\mathrm{F}}=100 \mathrm{~V}$ in $0.1 \mathrm{M} \mathrm{ABE}$ & 0.95 & -0.62
\end{tabular}

$\lambda=240 \mathrm{~nm}$ and $v_{\text {scan }}=10 \mathrm{mV} \mathrm{s}^{-1}$.

dark and under irradiation. This is a clear indication that the oxide behaves like an insulator, as found in the case of anodic films formed at the same formation voltage on Zr. Nevertheless, the inversion potential is more anodic than that measured for anodic films on pure zirconium. The photocharacteristics for thin $\left(U_{\mathrm{F}}=4 \mathrm{~V} / \mathrm{SCE}\right)$ and thick $\left(U_{\mathrm{F}}=100 \mathrm{~V}\right)$ films were fitted according to Eq. (3) (see Fig. 7b) and in Table 5 we report the best fitting exponents and the $V^{*}$ values as function of the formation voltage and of the anodizing/characterizing electrolyte. The dependence of $V^{*}$ values on the $\mathrm{pH}$ also for these films is in agreement with the theoretical expectations (see Eq. (4)). The supralinear behaviour of the anodic films on the alloy indicates that also for these oxides we are in presence of geminate recombination phenomena, more pronounced in the case of thinner films, when large changes in electric field values are obtained in the exploited electrode potential range.

We like to stress that the reported $U_{\mathrm{FB}}$ value of the anodic oxides on $\mathrm{Zr}-20$ at. \% Ti is $\sim 650 \mathrm{mV}$ more anodic that that estimated for $\mathrm{ZrO}_{2}$.

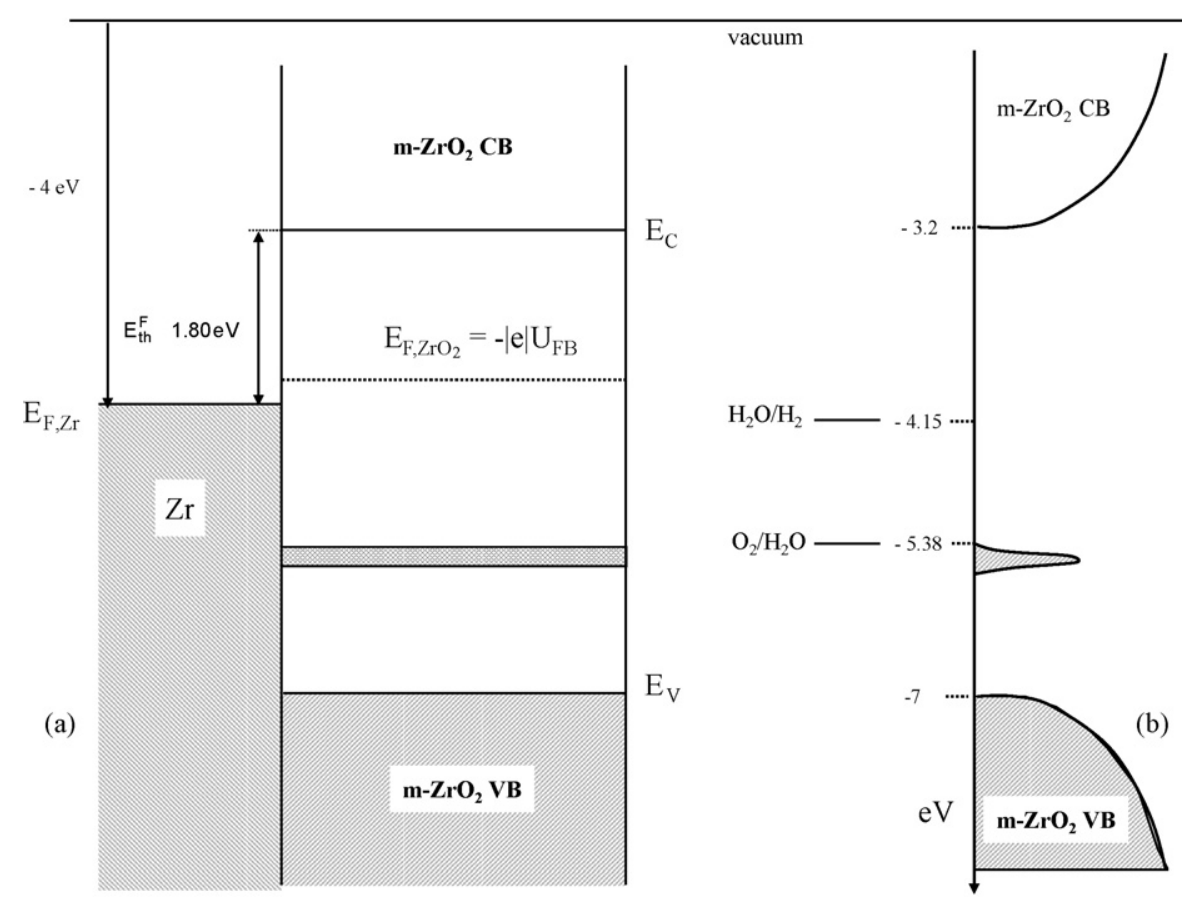

Fig. 7. (a) Schematic diagram of energy levels at metal/oxide/electrolyte interface for anodic films on sputter-deposited Zr. (b) Suggested density of states. 


\section{Discussion}

The experimental results previously outlined pertain to the photoelectrochemical behaviour of well-defined thick polycrystalline anodic films of $\mathrm{m}-\mathrm{ZrO}_{2}\left(U_{\mathrm{F}} \geq 50 \mathrm{~V}\right)$ as well as of thin films of zirconia with undetermined structure $\left(U_{\mathrm{F}} \leq 8 \mathrm{~V} / \mathrm{SCE}\right)$.

In order to reduce the possible interpretative hypotheses we first focus our attention on the crystalline films. PCS study evidenced the presence of two possible extrapolated band gap values at low $(\sim 3.3 \mathrm{eV})$ and high $(\sim 4.8 \mathrm{eV})$ photon energies. In this case we can attribute the photocurrent generated under illumination with high photon energy $(\lambda<260 \mathrm{~nm})$ to optical transitions occurring from occupied electronic states of the valence band to the empty states of the conduction band of the oxide. According to this we estimate a band gap of $4.8 \pm 0.05 \mathrm{eV}$ for polycrystalline $\mathrm{m}-\mathrm{ZrO}_{2}$, which is very close to those estimated by previous photoelectrochemical measurements [35-39] and within the range (actually very wide) of those theoretically predicted [14,18,26,31]. Moreover, this value is in agreement with that experimentally determined by EELS $[27,28,31,33]$ or by VUV [26,44] for monoclinic zirconia. According to the data of Tables 1 and 2, the same band gap value was derived for anodic films grown at electrode potential of $8 \mathrm{~V}$ (SCE), thus allowing to conclude that at this formation voltage the photoelectrochemical behaviour of anodic zirconia is similar to that showed by the monoclinic phase.

Lower $(4.4 \pm 0.1 \mathrm{eV})$ band gap values were estimated for thinner $\left(\leq 13 \mathrm{~nm}\right.$, see ref. [40]) films, i.e. air formed and $U_{\mathrm{F}} \leq 4 \mathrm{~V}$ (SCE). In this case it seems reasonable to attribute the lower optical gap to the absence of a long-range order, owing to the lack of a well-developed crystalline structure. In this case we should more properly discuss in terms of an optical mobility gap of the oxides. Even if the main contribution to the generated photocurrent usually arises from transitions involving extended states of valence and conduction bands, a minor contribution can be expected from optical transitions involving excitations of electrons from occupied localized states near the valence band edge to empty localized states near the conduction band. Mott and Davis [45] proved that, under the hypothesis of a linear distribution of the density of states in the band tails and by neglecting optical transitions between localized states, Eq. (1) gives a measure of the smaller energy difference between localized states of the valence band and extended states of the conduction band or vice versa, whichever is smaller. Thus, the lower $E_{\mathrm{g}}$ estimated for thinner films can be attributed to the presence of a finite density of states inside the mobility gap of the layers, which in turn can be related to the disordered structure of thin $\mathrm{ZrO}_{2}$.

Once stated that a band gap value of $\sim 4.8 \mathrm{eV}$ holds for crystalline anodic $\mathrm{m}-\mathrm{ZrO}_{2}$, the other important point pertains the origin of the sub-band gap photocurrent. According to the structural analysis (TEM and GIXRD) reported in ref. [40], there is no evidence of the presence of a hydrated external layer for anodic films grown to $100 \mathrm{~V}$ on sputtered $\mathrm{Zr}$, which are reported to be crystalline and mainly constituted by monoclinic zirconia. Thus, we can exclude that the formation of a hydrated lower band gap phase can be responsible of the inset of the sub-band gap photocurrent at $\sim 3.3 \mathrm{eV}$. In this case we have to take into account the possible presence of a band of defects, which are known to introduce electronic energy levels inside the forbidden gap of insulators.

The nature of these defects is very important since it determines the energy levels introduced into the band gap of the oxide. The most common point defects of cubic zirconia are oxygen vacancies, which accompany the presence of substitutional cations usually added to pure $\mathrm{ZrO}_{2}$ in order to stabilize at room temperature the high temperature stable polymorphs of zirconia [14]. In the case of monoclinic zirconia, we have also to consider other possible point defects, such as interstitial oxygen atoms. Foster et al. [22] calculated the energy location of such defects and, according to their results, oxygen vacancies and interstitial oxygen atoms can introduce energy levels inside the band gap of monoclinic zirconia between 0.8 and $2.2 \mathrm{eV}$ above the top of the valence band. This estimate allow us to sketch the energy levels of $\mathrm{Zr} / \mathrm{m}-\mathrm{ZrO}_{2} /$ electrolyte interface at $\mathrm{pH}=\mathrm{pH}_{\mathrm{pzc}}=5.9$ [46] of Fig. 7, where we also report the energy levels of the redox couples $\mathrm{H}_{2} \mathrm{O} / \mathrm{O}_{2}$ and $\mathrm{H}_{2} / \mathrm{H}_{2} \mathrm{O}$, directly involved in the generation of anodic and cathodic photocurrent, respectively.

The presence of a band of defects within the band gap of $\mathrm{m}$ $\mathrm{ZrO}_{2}$ can account for the onset of sub-band gap photocurrent at an energy threshold which depends on both the nature and concentration of defects and on their energetic level. According to our experimental findings indicating threshold energies for this process between 3.3 and $3.5 \mathrm{eV}$, we can represent the defects energy band as drawn in Fig. 7. We cannot exclude the presence of a density of allowed energy levels up to $2.2 \mathrm{eV}$ above the valence band, as predicted by the theory [22] even if we do not measure energy transition at energy lower than $3.3 \mathrm{eV}$. According to the PCS data, we assume an electron density of states represented by a Gaussian distribution with the maximum located between 1.3 and $1.5 \mathrm{eV}$ above the top of the valence band with a variable smearing factor, depending on the defect nature and concentration. It is important to stress that all the expected photo-reactions (water oxidation to oxygen and water reduction to hydrogen) are thermodynamically possible according to the scheme of Fig. 7.

Finally, we want to remark that according to energetic scheme of Fig. 7 the valence band edge is located at around $-7 \mathrm{eV}$ with respect to the vacuum level. This value is very close to that calculated for $\mathrm{Y}_{2} \mathrm{O}_{3}$, as expected since $\mathrm{Y}$ precedes $\mathrm{Zr}$ in the periodic table. In fact, we can roughly locate the top of the valence band (mainly derived from the $\mathrm{O}^{2-}-2 \mathrm{p}$ orbitals) of $\mathrm{Y}_{2} \mathrm{O}_{3}$ at $-6.9 \mathrm{eV}$ with respect to the vacuum level knowing its band gap [47] and internal photoemission threshold ( $\sim 2.1 \mathrm{eV}$, see ref. [41]).

The other important point to analyse pertains the interpretation of the photoelectrochemical response of anodic films on $\mathrm{Zr}-20$ at.\%Ti. According to the GIXRD experimental results reported in ref. [40], anodic films on this alloy have the crystalline structure of high temperature stable phase of $\mathrm{c}$ - or $\mathrm{t}-\mathrm{ZrO}_{2}$. Moreover, the RBS composition depth profile relating to $100 \mathrm{~V}$ anodic films on this alloy indicates that Ti is uniformly incorporated along the film thickness with a Ti/Zr ratio coincident with that of the base alloy. It is well known that tetragonal or cubic $\mathrm{ZrO}_{2}$ can be stabilized at room temperature by the addition of lower valence oxides (usually $\mathrm{Y}_{2} \mathrm{O}_{3}$ ) to form anion conduct- 
ing solid solutions in presence of oxygen vacancies [48-50]. Recently, it has been shown that also tetravalent cations have the same stabilizing effect, even if they do not create oxygen vacancies. It has been found that both oversized (i.e. Ce) and undersized (i.e. $\mathrm{Ge}, \mathrm{Ti}$ ) cations with respect to $\mathrm{Zr}^{4+}$ stabilize tetragonal zirconia and several mechanisms have been proposed in order to explain such a role [51-59]. As a consequence of the structural changes caused by $\mathrm{Ti}^{4+}$ into the $\mathrm{ZrO}_{2}$ lattice, several authors [53,55-57] report that a reduction of the free oxygen vacancies occurs in $\mathrm{TiO}_{2}$ doped zirconia. Thus, the lack of subband gap photocurrent for the anodic films on this alloy can be explained by the suppression of the defects band created by oxygen vacancies, due to their lower concentration. This fact can help also to explain the shift in the anodic direction of the flat band potential (i.e. electronic Fermi level) of the mixed oxide with respect to that of zirconia. In fact, a decrease in the donor concentration, caused by a diminished oxygen vacancy concentration, could account for the shift of the mixed oxide Fermi level toward the mid-gap region of the insulator and, thus, for the anodic shift of $U_{\mathrm{FB}}$.

The influence of the nature and/or the amount of the stabilizing agents on the band gap value of stabilized zirconia poses the problem on the estimate of the band gap of $\mathrm{t}-\mathrm{ZrO}_{2}$ [26], since the tetragonal polymorph is usually obtained at room temperature by doping. The experimental band gap values reported in the literature for tetragonal zirconia are usually obtained with yttria stabilized $\mathrm{t}-\mathrm{ZrO}_{2}$ [27] and we cannot exclude that they are in some way affected by the dopants. As far as we know, the only experimental band gap value reported in the literature for undoped $\mathrm{t}-\mathrm{ZrO}_{2}$ is in ref. [31], where a direct $E_{\mathrm{g}}$ of $5 \mathrm{eV}$ was estimated by EELS.

The direct band gap estimated by PCS for the Ti-Zr mixed oxide is lower than this value suggesting an influence on the band gap of the mixed oxide of the presence of titanium cations into the zirconium oxide lattice. In a previous work [47] it was proposed a correlation between the optical band gaps of crystalline oxides, $\mathrm{M}_{x} \mathrm{O}_{y}$, and the square of the electronegativity difference of their constituents, based on the assumption of a direct relation between the band gap and the single $\mathrm{M}-\mathrm{O}$ bond energy, obtained from the Pauling equation for the single bond energy.

With few exceptions the following fitting equations has been suggested to apply $[41,47]$ to $\mathrm{sp}$ and $\mathrm{d}$ metal oxides, respectively.

(sp) $\quad E_{\mathrm{g}}-\Delta E_{\mathrm{am}}(\mathrm{eV})=2.17\left(\chi_{\mathrm{M}}-\chi_{\mathrm{O}}\right)^{2}-2.71$

(d) $E_{\mathrm{g}}-\Delta E_{\mathrm{am}}(\mathrm{eV})=1.35\left(\chi_{\mathrm{M}}-\chi_{\mathrm{O}}\right)^{2}-1.49$

where $\Delta E_{\mathrm{am}}$ is a parameter which takes into account the influence of amorphous nature on the band gap of the oxides. For mixed oxides $\mathrm{A}_{\mathrm{a}} \mathrm{B}_{\mathrm{b}} \mathrm{O}_{y}$, it has been suggested that the previous correlation are still valid provided that the average single bond energy is estimated taking into account the contributions of both, $\mathrm{A}$ and $\mathrm{B}$, cations of the oxide trough an average cationic electronegativity parameter, $\chi_{\mathrm{M}}$, given by:

$\chi_{\mathrm{M}}=x_{\mathrm{a}} \chi_{\mathrm{A}}+x_{\mathrm{b}} \chi_{\mathrm{B}}$

where $\mathrm{A}$ and $\mathrm{B}$ are the metals of the oxide, and $x_{\mathrm{a}, \mathrm{b}}$ their cationic fractions. For $100 \mathrm{~V}$ anodic film on Ti-80 at. $\% \mathrm{Zr}$, according to the composition depth profile obtained by RBS [40], $x_{\mathrm{Ti}}=0.2$ and $x_{\mathrm{Zr}}=0.8$ can be inserted in Eq. (7). Concerning the electronegativity values, we assume and $\chi_{\mathrm{Ti}}=1.656$, obtained as the arithmetic mean between the electronegativity obtained by using Eq. (6b) from the band gap values of rutile and anatase [60], and $\chi_{\mathrm{Zr}}=1.35$ obtained by Eq. (6b) and in the experimental uncertainty admitted in the Pauling scale [61]. By using Eqs. (6b) and (7) a band gap of $4.40 \mathrm{eV}$ can be calculated, which agrees with the $E_{\mathrm{g}}$ value estimated by photocurrent spectroscopy in the hypothesis of direct optical transitions.

The possibility to detect both indirect and direct transitions is related to the electronic structure of the oxide, as discussed in ref. [62] for chemical vapour deposited diamond films. However, no theoretical studies are available on the influence of $\mathrm{Ti}^{4+}$ on the electronic structure of zirconia, which could help in understanding the reason of the simultaneous presence of both indirect and direct optical transitions.

The final aspect we like to comment is related to the presence or not of a surface layer of $\mathrm{Zr}(\mathrm{OH})_{4}$ on cast $\mathrm{Zr}$ metal. The data reported in Table 1 clearly indicate that on magnetron sputtered $\mathrm{Zr}$ the low band gap transitions at $3.5 \pm 0.05 \mathrm{eV}$ are independent on the anodizing solution $\mathrm{pH}(0.3 \leq \mathrm{pH} \leq 13)$ and water content (very low in SAAC). This finding is in agreement with the previously discussed suggestion that a defects band is formed also in the case of thin anodic films. However, in ref. [37] it was shown that in several cases the surface films displayed indirect optical band gap values appreciably lower $(2.70 \mathrm{eV})$ than that reported in Tables 1 and 2 . The $2.70 \mathrm{eV}$ transition is still compatible with the hypothesis of Foster et al. [22] of a band of defects more extended in energy (up to $2.2 \mathrm{eV}$ above the valence band), which can be formed on mechanical treated $\mathrm{Zr}$ but it does not rule out the possible presence of a very thin hydroxide layer on the surface of anodized $\mathrm{Zr}$ metal. Further investigation on well characterized $\mathrm{Zr} / \mathrm{Zr}(\mathrm{OH})_{4} /$ electrolyte interface could help to get a deeper understanding of the photoelectrochemical behaviour of passive films on cast zirconium.

\section{Conclusions}

A photoelectrochemical investigation of anodic films grown on sputter-deposited $\mathrm{Zr}$ and $\mathrm{Zr}-20$ at.\% Ti was carried out, which allowed to get information on their electronic properties (band gap and flat band potential).

The results relating thick $\left(U_{\mathrm{F}} \geq 50 \mathrm{~V}\right)$ anodic films were related to their crystalline structure and were compared with those obtained for thinner $\left(U_{\mathrm{F}} \leq 8 \mathrm{~V} / \mathrm{SCE}\right)$ anodic oxides with undetermined crystalline structure and with previous photoelectrochemical data on anodic zirconia grown on cast $\mathrm{Zr}$ after mechanical and/or chemical cleaning.

The comparison between the photoelectrochemical behaviour of anodic films on $\mathrm{Zr}$ and $\mathrm{Zr}-20$ at.\% Ti sputterdeposited alloys evidenced a marked influence of the presence of $\mathrm{Ti}^{4+}$ on both the band gap and flat band potential of the mixed oxide with respect to pure $\mathrm{m}-\mathrm{ZrO}_{2}$. The observed decrease in the $E_{\mathrm{g}}$ agrees well with the theoretical expectation according to the correlation between the band gap of metal oxides and the difference of electronegativity of their constituents [47], while 
the anodic shift of $U_{\mathrm{FB}}$ agrees with the reported decrease of oxygen vacancies concentration in Ti stabilized $\mathrm{t}-\mathrm{ZrO}_{2}$.

\section{References}

[1] T. Ishikawa, H. Yamaok, Y. Harada, T. Fujii, T. Nagasawa, Nature 416 (2002) 64.

[2] S. Meriani, Zirconia 88. Advances in Zirconia Science and Technology, Elsevier, New York, 1989.

[3] E.J. Walter, S.P. Lewis, A.M. Rappe, Surf. Sci. 495 (2001) 44.

[4] A. Meldrum, L.A. Boatner, R.C. Ewing, Phys. Rev. Lett. 88 (2002) 025503.

[5] C. Morant, J.M. Sanz, L. Galán, Phys. Rev. B 45 (1992) 1391.

[6] J.H. Ai, Y.Z. Chen, M. Urquidi-Macdonald, D.D. Macdonald, J. Electrochem. Soc. 154 (2007) C43.

[7] J.H. Ai, Y.Z. Chen, M. Urquidi-Macdonald, D.D. Macdonald, J. Electrochem. Soc. 154 (2007) C52.

[8] V. Fiorentini, G. Gulleri, Phys. Rev. Lett. 89 (2002) 266101.

[9] R. Puthenkovilakam, E.A. Carter, J.P. Chang, Phys. Rev. B 69 (2004) 155329.

[10] R. Orlando, C. Pisani, C. Roetti, E. Stefanovich, Phys. Rev. B 45 (1992) 592.

[11] S. Gennard, F. Cora, C.R.A. Catlow, J. Phys. Chem. B 103 (1999) 10158.

[12] J.K. Dewhurst, J.E. Lowther, Phys. Rev. B 57 (1998) 741.

[13] J.E. Lowther, J.K. Dewhurst, J.M. Leger, J. Haines, Phys. Rev. B 60 (1999) 14485 .

[14] B. Králik, E.K. Chang, S.G. Louie, Phys. Rev. B 57 (1998) 7027.

[15] H.J.F. Jansen, Phys. Rev. B 43 (1991) 7267.

[16] G. Jomard, T. Petit, A. Pasturel, L. Magaud, G. Kresse, J. Hafner, Phys. Rev. B 59 (1999) 4044.

[17] H.J.F. Jansen, J.A. Gardner, Physica B \& C 150B (1988) 10.

[18] F. Zandiehnadem, R.A. Murray, W.Y. Ching, Physica B \& C 150B (1988) 19.

[19] N.I. Medvedeva, V.P. Zhukov, M.Y. Khodos, V.A. Gubanov, Phys. Status Solidi B 160 (1990) 517.

[20] E.V. Stefanovich, A.L. Shluger, C.R.A. Catlow, Phys. Rev. B 49 (1994) 11560.

[21] G. Stapper, M. Bernasconi, N. Nicoloso, M. Parrinello, Phys. Rev. B 59 (1999) 797.

[22] A.S. Foster, V.B. Sulimov, F. Lopez Gejo, A.L. Shluger, R.M. Nieminen, Phys. Rev. B 64 (2001) 224108

[23] S. Ostanin, E. Salamatov, A.J. Craven, D.W. McComb, D. Vlachos, Phys. Rev. B 66 (2002) 132105.

[24] A. Bogicevic, C. Wolverton, Phys. Rev. B 67 (2003) 024106.

[25] A. Eichler, Phys. Rev. B 64 (2001) 174103.

[26] R.H. French, S.J. Glass, F.S. Ohuchi, Y.N. Xu, W.Y. Ching, Phys. Rev. B 49 (1994) 5133.

[27] D.W. McComb, Phys. Rev. B 54 (1996) 7094.

[28] J. Frandon, B. Brouseau, F. Pradal, Phys. Status Solidi B 98 (1980) 379.

[29] F. Yubero, J.M. Sanz, J.F. Trig, E. Elizalde, S. Toogard, Surf. Interface Anal. 22 (1994) 124.

[30] F. Yubero, J.P. Espinos, A.R. Gonzalez-Elipe, J. Vac. Sci. Technol. A 16 (1998) 2287.
[31] L.K. Dash, N. Vast, P. Baranek, M.C. Cheynet, L. Reining, Phys. Rev. B 70 (2004) 245116.

[32] C.K. Kwok, C.R. Aita, J. Appl. Phys. 66 (1989) 2756.

[33] E. Elizalde, J.M. Sanz, F. Yubero, L. Galan, Surf. Interface Anal. 16 (1990) 213.

[34] M. Li, Z. Feng, G. Xiong, P. Ying, Q. Xin, C. Li, J. Phys. Chem. B 105 (2001) 8107.

[35] A.R. Newmark, U. Stimming, Langmuir 3 (1987) 905.

[36] A. Goossens, M. Vazquez, D.D. Macdonald, Electrochim. Acta 41 (1996) 47.

[37] (a) F. Di Quarto, S. Piazza, C. Sunseri, M. Yang, S.M. Cai, Electrochim. Acta 41 (1996) 2511; (b) S. Piazza, C. Sunseri, F. Di Quarto, Corrosion 58 (2002) 436.

[38] B.Y. Kim, C.J. Park, H.S. Kwon, J. Electroanal. Chem. 576 (2005) 269.

[39] S.J. Lee, E.A. Cho, S.J. Ahn, H.S. Kwon, Electrochim. Acta 46 (2001) 2605.

[40] H. Habazaki, K. Shimizu, S. Nagata, K. Asami, K. Takayama, Y. Oda, P. Skeldon, G.E. Thompson, Thin Solid Films 479 (2005) 144.

[41] F. Di Quarto, S. Piazza, M. Santamaria, C. Sunseri, in: H.S. Nalwa (Ed.), Handbook of Thin Film Materials, vol. 2, Academic Press, San Diego, 2002, p. 373 (Chapter 8).

[42] H. Gerischer, Electrochim. Acta 34 (1989) 1005.

[43] (a) R. Crandall, J. Appl. Phys. 54 (1983) 7176; (b) F. Di Quarto, S. Piazza, R. D’Agostino, C. Sunseri, J. Electroanal. Chem. 228 (1987) 119

[44] R.S. Sokolova, Sov. J. Appl. Phys. 41 (1974) 454.

[45] N.F. Mott, E.A. Davis, Electronic Processes in Non-Crystalline Materials, 2nd ed., Claredon Press, Oxford, 1979.

[46] E. McCafferty, J. Electrochem. Soc. 146 (1999) 2863.

[47] F. Di Quarto, S. Piazza, C. Sunseri, M.C. Romano, J. Phys. Chem. B 101 (1997) 2519

[48] S.M. Ho, Mater. Sci. Eng. 54 (1982) 23.

[49] P. Li, I.-W. Chen, J.E. Penner-Hann, Phys. Rev. B 48 (1993) 10074.

[50] P. Li, I.-W. Chen, J.E. Penner-Hann, J. Am. Ceram. Soc. 77 (1994) 118.

[51] P. Li, I.-W. Chen, J.E. Penner-Hann, J. Am. Ceram. Soc. 77 (1994) 1281.

[52] E. Zschech, P.N. Kountouros, G. Petzow, P. Behrens, A. Lessmann, R. Frahm, J. Am. Ceram. Soc. 76 (1993) 197.

[53] L.S.M. Traqueia, T. Pagnier, F.M.B. Marques, J. Eur. Ceram. Soc. 17 (1997) 1019.

[54] M. Valigi, D. Gazzoli, E. Incocciati, R. Dragone, Solid State Ionics 101 (1997) 597.

[55] F. Capel, C. Moure, P. Duran, A.R. Gonzalez-Elipe, A. Caballero, J. Mater. Sci. 35 (2000) 345

[56] S.N.B. Hodgson, J. Cawley, J. Mater. Proc. Technol. 119 (2001) 112.

[57] M.T. Colomer, J.R. Jurado, J. Solid State Chem. 165 (2002) 79.

[58] G.M.S. El Shafei, A.A. Zahran, Adsorpt. Sci. Technol. 20 (2002) 707.

[59] A.B. Panda, J.C. Roy, P. Pramanik, J. Eur. Ceram. Soc. 23 (2003) 3043.

[60] M. Santamaria, F. Di Quarto, P. Skeldon, G.E. Thompson, J. Electrochem. Soc. 153 (2006) B518.

[61] L. Pauling, The Nature of Chemical Bond, Cornell University Press, New York, London, 1973.

[62] B. Rafferty, L.M. Brown, Phys. Rev. B 58 (1998) 10362 